\title{
Identification of changes in kinematics and electromyographic parameters during dual-task gait: a comparative study between young and elderly female subjects
}

\author{
Identificação de alterações nos parâmetros cinemáticos \\ e eletromiográficos durante marcha com dupla-tarefa: \\ um estudo comparativo entre jovens e idosas
}

\author{
Camilla Zamfolini Hallal ${ }^{[a],[b]}$, Deborah Hebling Spinoso ${ }^{[b]}$, Mary Hellen Morcelli ${ }^{[b]}$, \\ Ligia Cristiane Fonseca $^{[b]}$, Mauro Gonçalves ${ }^{[b]}$, Nise Ribeiro Marques $^{[b] *}$ \\ [a] Faculdade de Educação Física e Fisioterapia, Universidade Federal de Uberlândia (FAEFI-UFU), Uberlândia, MG, Brazil. \\ [b] Universidade do Estadual Paulista (UNESP), Instituto de Biociências, Rio Claro, SP, Brazil.
}

\section{Abstract}

Introduction: Falls during gait are one of the leading causes of death and injuries in elderly adults. Objective: This study aimed to compare the performance of young (YG) and elderly (EG) adults during dual-task gait (using a traffic light simulator) according to kinematics and electromyographic parameters. Materials and methods: 17 young and 18 elderly physically fit female subjects participated in this study. The volunteers walked on a treadmill under two different conditions: normal gait (M1) and dual-task gait

* CZH: PhD, e-mail: camillazhallal@yahoo.com.br DHS: MSc, e-mail: deborahebling@yahoo.com.br MHM: PhD, e-mail: mary_morcelli@yahoo.com.br LCF: MSc, e-mail: ligiafonseca@terra.com.br MG: PhD, e-mail: maurog@unesp.br NRM: PhD, e-mail: nisermarques@yahoo.com.br 
(M2). We recorded EMG signals from the rectus femoris (RF), vastus medialis (VM), vastus lateralis (VL), biceps femoris (BF), tibialis anterior (TA), gastrocnemius lateralis (GL) and soleus (SO). The following kinematic data were obtained: step length, step time and self-selected velocity. Data analysis was performed using Wilcoxon's, Mann-Whitney, T-student tests and T-student for independent samples. The level of significance was set at $\mathrm{p}<0.05$. Results: For both groups, there was greater muscle activation of the RF, VM, VL, BF and SO during M2 than during M1. The YG showed lower muscle activation of the RF, VM, BF and SO during M2 when compared to EG. The EG had smaller step length than the YG. The step length values detected during M1 were higher than the ones collected during M2. During M2, the YG showed higher step time compared to the EG. Elderly subjects walked at a lower self-selected velocity than young subjects. Conclusions: Our findings suggest that dual-task gait modify the neuromuscular behavior in elderly subjects, increasing the risk of falls.

Keywords: Biomechanics. Electromyography. Kinematics. Gait.

\section{Resumo}

Introdução: Quedas são eventos frequentes durante a marcha e são consideradas as principais causas de morte e lesões em idosos. Objetivos: O presente estudo teve por objetivo comparar o desempenho de jovens (GJ) e idosas (GI) durante a marcha com dupla tarefa cotidiana (simulador de semáforos) por meio de parâmetros cinemáticos e eletromiográficos. Materiais e métodos: Participaram do estudo 17 jovens e 18 idosas ativas. As voluntárias andaram sobre esteira em 2 condições distintas: marcha normal (M1) e marcha dupla tarefa (M2). Os sinais eletromiográficos foram coletados dos músculos reto femoral (RF), vasto medial (VM), vasto lateral (VL), bíceps femoral (BF), tibial anterior (TA), gastrocnêmio lateral (GL) e sóleo (SO). Os dados cinemáticos analisados foram comprimento de passada, tempo de passada e velocidade de preferência. Para a análise dos dados foram usados os testes de Wilcoxon, Mann-Whitney, o teste T-student e o T-student para amostras independentes. Foi adotado nível de significância de $p<0,05$. Resultados: Os músculos RF, VM, VL, BF e SO apresentaram ativação muscular maior na condição M2 em relação à condição M1 no GI e GJ. O GJ apresentou ativação muscular menor do RF, VM, BF e SO na condição M2 que GI. Na condição M1 os valores de comprimento de passada encontrados foram maiores que na condição M2. O tempo de passada para o GJ na condição M2 foi maior do que para o GI. Conclusões: Os idosos apresentaram velocidade de preferência menor que jovens. Nossos resultados sugerem que a marcha associada à dupla tarefa cotidiana, altera o comportamento neuromuscular do idoso, aumentando assim o risco de quedas.

Palavras-chave: Biomecânica. Eletromiografia. Cinemática. Marcha.

\section{Introduction}

The aging process causes functional and structural changes in the body such as changes in sensory, motor and musculoskeletal systems, which compromise a person's ability to perform complex motor tasks and affect the performance of daily life activities $(1,2)$. The combination of these aging-associated changes greatly increases the risk of falls for older adults (2).

Fall is defined as an accidental event which results in an individual coming or dropping down to a lower position in relation to the start position (3). Falls are one of the leading causes of death and injuries in elderly adults, and account for about $45 \%$ of cases of death in this population (4). In Brazil, it is estimated that about 4.32 million elderly fall each year and, of these, 2.175 million suffer some kind of fall-retaled consequence (5). The occurrence of falls is potentially harmful because it contributes to the emergence of health problems and results in decreased quality of life and reduced social activities (6).

Studies show that over $50 \%$ of cases of falls occur during gait. Therefore, the ability to walk efficiently and safely is important for older people to maintain independence and avoid falls (7-9). In order to ensure balance and stability during gait, older adults 
use some adaptive strategies such as reduced speed, reduced stride length, reduction of the swing phase duration and decreased joint motion of the hip, knee and ankle $(9,10)$.

When gait is performed simultaneously with other cognitive or motor tasks, the performance of both tasks may be negatively affected because walking requires attention and high levels of cognition to estimate, plan and execute (11). Thus, if gait is performed in concurrence with another task, postural changes that increase the risk of falls may occur $(4,12,13)$. Studies show that the influence of dual tasks on postural control is bigger when the level of complexity of the task is high. Nevertheless, postural changes can also be observed during the performance of simple tasks such as daily living tasks (12).

Falls in the elderly can be prevented through the early detection of aging-related biomechanical changes that may alter gait pattern (14). Thus, the identification of temporal and spatial kinematic changes in gait patterns caused by the performance of dual tasks and the assessment of lower limbs muscle activity in the elderly provide aids to guide the implementation of physical therapy intervention strategies. In this sense, the aim of this study is to compare the performance of young and elderly female adults during dual-task gait according to kinematics and electromyographic parameters. Although there are a few studies in the literature investigating dual-task gait in elderly and young people, there are no studies assessing kinematics and electromyographic variables during dual-task gait using of a traffic light simulator, as in this study. Thus, we hypothesized that when young and elderly adults perform dual-task gait, there is higher muscle activation of the lower limbs and more pronounced changes in step length and step time in the elderly when compared to young adults.

\section{Materials and Methods}

\section{Participants}

35 female volunteers participated in this study. They were divided into two groups according to their age: the young group (YG) and the elderly group (EG). The YG was composed of 17 female, physically active university students with a mean age of $21.47 \pm 2.06$ years. The EG was composed of 18 female, physically active subjects at low risk of falls, with an average age of $65.33 \pm 3.14$ years and recruited from a physical activity community group for older adults. EG participants were classified according to their risk of falls using the Berg Balance Scale, which consists of 14 tasks involving static and dynamic balance control during the performance of functional tasks. The final score obtained on the scale predicts the risk of falls in the assessed elderly subjects (15). All elderly participants were at low risk of falls according to the Berg Balance Scale. The volunteers' characteristics are summarized in Table 1.

Table 1 - Volunteers' characteristics

\begin{tabular}{lccc}
\hline & Young adults & Elderly adults & $p$ \\
\hline Age (years) & $21.47( \pm 2.06)$ & $65.33( \pm 3.14)$ & $0.00^{*}$ \\
Body mass $(\mathrm{Kg})$ & $60.68( \pm 5.93)$ & $64.00( \pm 1.55)$ & 0.23 \\
Height $(\mathrm{m})$ & $1.63( \pm 0.05)$ & $1.55( \pm 0.05)$ & $0.00^{*}$ \\
Self-selected velocity $(\mathrm{m} / \mathrm{s})$ & $0.95( \pm 0.84)$ & $0.70( \pm 1.92)$ & $0.00^{*}$ \\
\hline
\end{tabular}

Note: * Significant values $(p<0.05)$.

The inclusion criteria were based on the studies by Hahn, Lee and Chou (10) and Abbud, Li and Demont (11). These were presence of pain, fracture or serious injury to soft tissues in the six months preceding the study; and presence of neurological, cardiovascular or respiratory changes. Volunteers who reported dizziness or physical discomfort during the tests were excluded. This study was approved by the local Research Ethics Committee. 


\section{Instruments}

EMG signals were recorded with a 16-channel telemetric EMG system (Noraxon ${ }^{\circledR}$ MyoResearch, USA) and further analyzed with Myoresearch software (Noraxon ${ }^{\circledR}$, USA). Kinematic data were collected in sagittal plane using a digital camera (NV-GS320 Panasonic ${ }^{\circledR}$ ) at $100 \mathrm{fps}$ and an image analysis software (Vicon ${ }^{\circledR} 9.0$ - Peak Motus). The gait test was performed on a Millennium Super ATL (INBRAMED ${ }^{\circledR}$ ) treadmill.

\section{Procedures}

EMG signals were collected throughout the gait test period. Surface electrodes (Ag/AgCl; Meditrace ${ }^{\circledR}$ ) were arranged in bipolar configuration torecord surface EMGs for the following muscles, considering the Surface EMG for the Non Invasive Assessment of Muscles (SENIAM) rules: rectus femoris (RF), vastus medialis (VM), vastus lateralis (VL), biceps femoris $(\mathrm{BF})$, tibialis anterior (TA), gastrocnemius lateralis (GL) and soleus (SO) (16).

Kinematic data were collected in the sagittal plane with reflective markers placed on the right lateral malleolus and left medial malleolus, and between the first and second (right and left) metatarsals.

Before starting the gait test, the subjects got familiarized with the treadmill by walking on it at their self-selected velocity (17). After familiarization, the test was started and volunteers walked on the treadmill under two different conditions.

During the first condition (normal gait, M1), the volunteers were asked to walk on the treadmill at their self-selected velocity for three consecutive minutes. The second condition (dual-task gait, M2) was tested after M1. During M2, the volunteers were instructed to walk on the treadmill at their self-selected velocity and, at the same time, pay attention to a random system of colored lights, similar to a traffic light. The instructions were to name the colors as the lights lit and they appeared.

\section{Data analysis}

Data analysis was performed using 10 consecutive gait cycles performed during M1 and M2. The beginning and the end of the cycles were determined according to the moment when there was the greatest distance between the reflective markers placed on the right malleolus and the left metatarsus (when the right calcaneus touches the ground), according to protocol adapted Kang \& Dingwell (18).

EMG signals were collected at a $1000 \mathrm{~Hz}$ sampling frequency and processed in MATLAB 7.0 ${ }^{\circledR}$. To create the linear envelope, we used a high pass filter of $20 \mathrm{~Hz}$, a low pass of $500 \mathrm{~Hz}$ to $6 \mathrm{kHz}$ and a notch of $60 \mathrm{~Hz}$. The rectified data were interpolated at 1001 points on the ten gait cycles of each gait condition. All the linear envelope values were normalized by the mean values obtained for each muscle during normal gait.

The following kinematic data were obtained: step length, step time and self-selected velocity. Data were collected at a sampling frequency of $100 \mathrm{fps}$ and processed using an image analysis software (Vicon ${ }^{\circledR} 9.0$ Peak Motus). The step length values were normalized by the size of the right lower limb of each volunteer.

Statistical analysis was performed using PASW statistics $18.0^{\circledR}$. Regarding the analysis of muscle activation data, the Wilcoxon's test was used to compare the two different gait conditions within the same group and the Mann-Whitney test was used for comparisons between groups. With regard to the analysis of step length and step time, the T-student test was used to compare the two different gait conditions within the same group and the T-student for independent samples was used for comparisons between groups. Self-selected velocity data were analyzed using Mann-Whitney test. The level of significance was set at $\mathrm{p}<0.05$.

\section{Results}

For both groups, there was significantly greater muscle activation of the RF, VM, VL, BF and SO during M2 than during M1. The EG showed $\mathrm{p}=0.000$ for RF, $\mathrm{VM}, \mathrm{VL}, \mathrm{BF}$ and SO. The YG showed $\mathrm{p}=0.000$ for RF, $\mathrm{VM}, \mathrm{VL}$ and $\mathrm{SO}$ and $\mathrm{p}=0.024$ for BF.

During M1, the EG showed significantly greater muscle activation of RF, VM, VL, BF, TA, GL and SO ( $p=$ $0.002 ; \mathrm{p}=0.006 ; \mathrm{p}=0.000 ; \mathrm{p}=0.004 ; \mathrm{p}=0.024 ; \mathrm{p}=$ 0.030 ; and $p=0.001$, respectively) than the YG. The YG showed significantly lower muscle activation of the RF, VM, BF and SO during M2 when compared to $\mathrm{EG}(\mathrm{p}=0.005 ; \mathrm{p}=0.006, \mathrm{p}=0.000$, and $\mathrm{p}=0.000$, respectively). Figure 1 shows maximum, minimum and median values of muscle activation of RF, VM, VL, BF, TA, GL and SO, respectively, for the YG and EG during M1 and M2. 



Figure 1 - Median and quartiles values of muscle activation of RF, VM, VL, BF, TA, GL and SO for the EG and YG during normal gait and dual-task gait

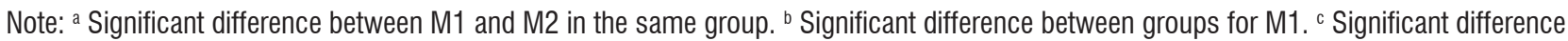
between groups for M2. 
The EG had smaller step length than the YG during M1 and M2 ( $p=0.005$ and $p=0.001$, respectively). Within the same group, only the EG showed significant differences between the results collected during M1 and M2 ( $p=0.001)$. The step length values detected during $\mathrm{M} 1$ were higher than the ones collected during M2 (Figure 2).

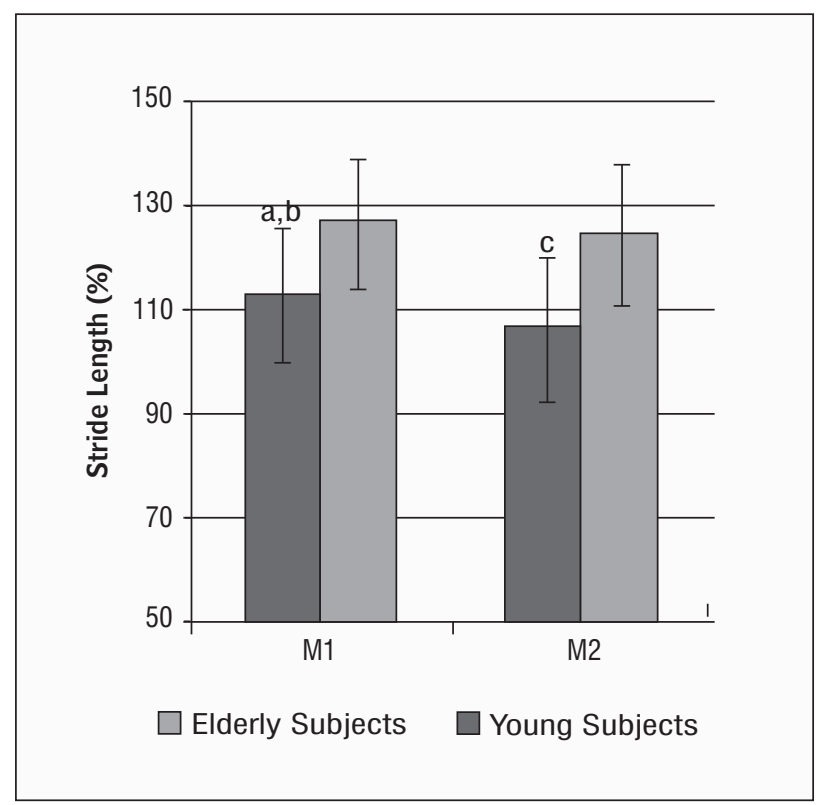

Figure 2 - Normalized values of step length

Note: a Significant difference between M1 and M2 in the same group.

b Significant difference between groups for M1. ' Significant difference between groups for M2.

During M2, the YG showed significantly higher step time compared to the EG $(p=0.003)$. There was no significant difference between normal gait and dualtask gait in the same group ( $p=0.197$ for the EG and $\mathrm{p}=1.000$ for the YG), nor significant difference between groups during normal gait $(p=0.194)$. Table 2 shows the mean and standard deviation values of step time for the EG and the YG during M1 and M2.

The results show a significant difference in selfselected velocity between EG and YG, $\mathrm{p}=0.000$ (Figure 3).

Although risk factors for falls are multifactorial, more than $50 \%$ of falls in older persons occur during walking $(7,8)$. The impact of cognitive function on gait pattern has been extensively studied in the last decade, as this activity is no longer considered to be an automatic task, but rather an activity with a growing recognition of cognition $(19,20)$.
Table 2 - Mean and standard deviation values of step time for young and elderly adults during normal gait and dual-task gait.

\begin{tabular}{lcc}
\hline & Young adults & Elderly adults \\
\hline Normal gait & $1.175( \pm 0.086)$ & $1.129( \pm 0.130)$ \\
Dual-task gait & $1.160 *( \pm 0.086)$ & $1.055( \pm 0.114)$ \\
\hline
\end{tabular}

Note: ${ }^{*}$ Significant difference between groups during dual-task gait.

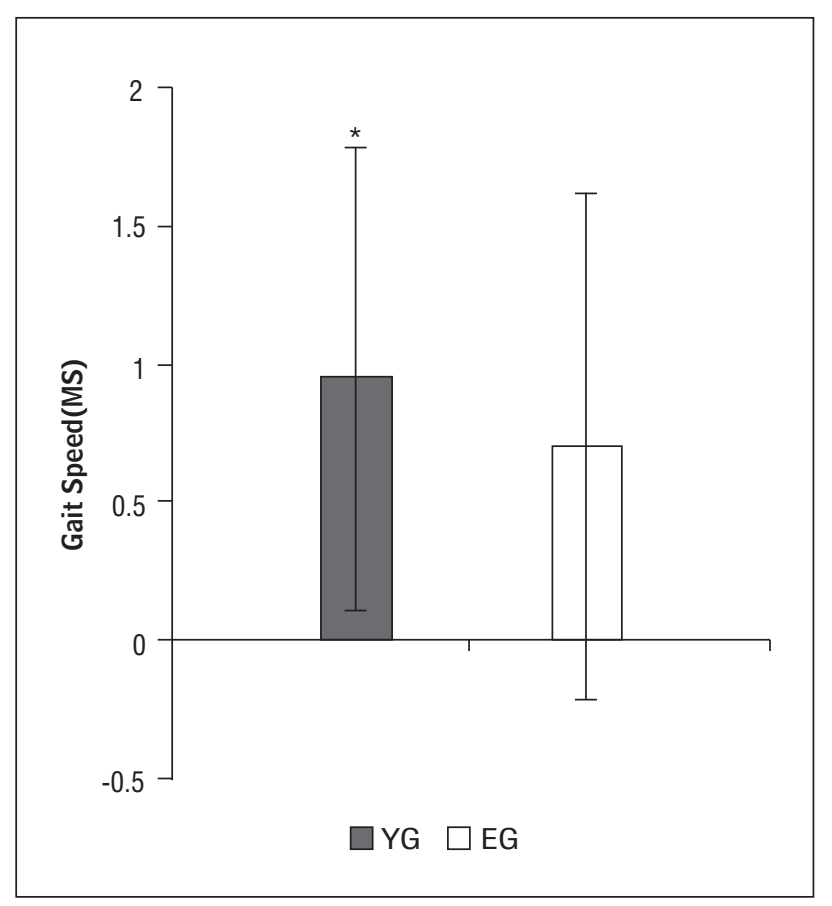

Figure 3 - Self-selected velocity $(\mathrm{m} / \mathrm{s})$ of the $\mathrm{YG}$ and EG Note: ${ }^{*}$ Significant difference $(p \leq 0.05)$.

The performance of a (cognitive or motor) dualtask during gait may affect the performance of both activities, depending on neuropsychological and motor resources, and on the priority and complexity of the tasks (21). Some authors claim that, when elderly people are exposed to situations that involve the simultaneous performance of motor and cognitive tasks, changes in postural control may occur, increasing the risk of falls in this population (4-13). Thus, the aim of this study is to compare the performance of young and elderly female adults during dual-task gait according to kinematics and electromyographic parameters.

The results show that, for both groups, there was significantly greater muscle activation of the RF, VM, 
VL, BF and SO during M2 than during M1. According to a study conducted by Nadkarni et al. (22), changes in gait parameters due to the simultaneous performance of cognitive tasks occur both in young and in elderly adults, although the gait adaptation strategy employed to maintain balance is different between these two groups. However, due to aging-related changes in sensory and motor functions, dual-task situations may represent a potential increased risk of falls for the elderly, given their reduced capacity to adapt when faced with challenging tasks $(1-23,24)$.

During M1, the EG showed significantly greater muscle activation of all assessed muscles (RF, VM, VL, $\mathrm{BF}, \mathrm{TA}, \mathrm{GL}$ and $\mathrm{SO}$ ) than the YG, which may indicate a deterioration of gait function in the elderly. Kang \& Dingwell (25) assessed the electromyographic activity in the VL, BF, TA and GM muscles (medial gastrocnemius) of the lower limbs during normal gait in young and elderly patients, and found greater muscle activation of the VL, BF and GM in the last group of patients. These results can be explained by the fact that elderly people must use a greater percentage of their maximum strength to perform daily activities, and thus, even during normal gait, they tend to activate more motor units than young individuals to walk safely (26).

During M2, the EG had greater muscle activation of the RF, VM, VL, BF and SO than the YG, which shows that elderly people need to make greater neuromuscular adjustments to maintain dynamic balance during the performance of challenging tasks (27). As a result of this increased neuromuscular demand during the performance of activities that require a greater control over movements to maintain balance, the elderly are more prone to developing muscle fatigue during gait, which enhances the risk of falls (28).

We found a significant difference in step length between the EG and the YG during M1 and M2. With regard to differences within the same group, only the EG showed significant differences between the results collected during M1 and M2. We found no significant differences in step time within the same group between $\mathrm{M} 1$ and $\mathrm{M} 2$ or between the EG and the YG during M1. However, during M2, the EG showed significantly lower step time compared to the YG. Both the step time and the step length reflect the control over the rhythmic mechanism of the step. Thus, changes in kinematic variables during normal gait or dual-task gait indicate possible adjustments to maintain balance $(13,29,30)$. Attention is a cognitive resource that is necessary for proper gait performance. Therefore, activities that compromise attention may be associated with postural instability and disturbances in the performance daily living tasks, and may lead to falls (20).

Montero-Odasso et al. (31) have examined kinematic variables in elderly patients with mild cognitive impairment during normal gait and dual-task gait. Contrary to the results of this study, these authors found higher step time during dual-task gait. This difference may be due to the fact that, in the aforementioned study, gait analysis was performed on a platform, while in this study a treadmill was used. Thus, because subjects exercised at a constant treadmill velocity throughout the test (self-selected velocity), only a limited number of kinematic adjustments due to speed changes have been made. This may have caused a reduction in step time that was probably due to an increase in cadence.

Another significant finding was that elderly subjects walked at a lower self-selected velocity than young subjects, which is in line with studies by Beauchet et al. (32) and Yogev-Seligmann et al. (33). Verghese et al. believe that a $10 \mathrm{~cm} / \mathrm{s}$ decrease in gait velocity may be associated with a $7 \%$ increase in the risk of falls. In a study conducted by Kang \& Dingwell (25), self-selected velocity was similar in the young and elderly groups. This discrepancy between the results of the two studies is probably mainly due to individual characteristics of participants.

Although steps were taken to ensure maximum standardization of methodological procedures in this study, there are some limitations related to the interpretation of the results. The elderly women who participated in this study were classified as being at low risk for falls (Berg Balance Scale) and were physically active. Thus, as these characteristics may significantly interfere with the performance of the proposed tasks, the extrapolation of the results to sedentary elderly subjects and/or to elderly populations at high risk for falls should be done with caution.

\section{Conclusion}

In accordance with the proposed objectives of this paper, we did identify changes in kinematics and electromyographic parameters of young and elderly subjects during normal gait and dual-task gait. Thus, we conclude that age-related changes in dual-task 
gait patterns also alter the neuromuscular behavior of the elderly, affecting their ability to maintain dynamic balance during gait and thereby increasing the risk of falls.

Given that the identification of aging-related biomechanical changes in gait can help in the implementation of strategies for falls prevention among older people, it is suggested that further studies are conducted with sedentary elderly subjects at high risk of falls, addressing the performance of other everyday tasks during gait.

\section{Acknowledgments}

We are grateful to the CNPq, FAPESP and Fundunesp for their financial support.

\section{References}

1. Kerrigan DC, Todd MK, Croce UD, Lipsitz LA, Collins JJ. Biomechanical gait alterations independent of speed in the healthy elderly: evidence for specific limiting impairments. Arch Phys Med Rehabil. 1998;79:317-22.

2. Yen HC, Chen HL, Liu MW, Liu HC, Lu TW. Age effects on the inter-joint coordination during obstacle-crossing. J Biomech. 2009;42:2501-6.

3. Tucker MG, Kavanagh JJ, Morrison S, Barrett RS. What are the relations between voluntary postural sway measures and falls-history status in community-dwelling older adults? Arch Phys Med Rehabil. 2010;91:750-8.

4. Schultz BW, Lloyd JD, William E. The effects of everyday concurrent task on overground minimum toe clearance and gait parameters. Gait \& Posture. 2010;32(1):18-22.

5. Abreu SSE, Caldas CP. Velocidade de marcha, equilíbrio e idade: um estudo correlacional entre idosas praticantes e idosas não praticantes de um programa de exercícios terapêuticos. Braz J Phys Ther. 2008;12(4):324-30.

6. Van Dieën JH, Pijnappels M. Falls in older peoples. J Electromyogr Kinesiol. 2008;18:169-71.
7. Talbot LA, Musiol RJ, Witham EK, Metter EJ. Falls in young, middle-aged and older community dwelling adults: perceived cause, environmental factors and injury. BMC Public Health. 2005;5:86.

8. Hollman JH, Youdas JW, Lanzino DJ. Gender differences in dual task gait performance in older adults. Am J Mens Health. 2009;22.

9. Hahn ME, Chou LS. Age-related reduction in sagittal plane Center of mass motion during obstacle crossing. J Biomech. 2004;37:837-44.

10. Hahn ME, Lee HJ, Chou LS. Increased muscular challenge in older adults during obstructes gait. Gait \& Posture. 2005;22:356-61.

11. Abbud GAC, Li KZH, Demont RG. Attentional requeriments of walking according to the gait phase and onset of auditory stimuli. Gait \& Posture. 2009;30:227-32.

12. Daele UV, Hagman F, Truijen S, Vorlat P, Gheluwe BV, Vaes P. Decreased in postural sway and trunk stiffness during cognitive dual-task in nonspecific chronic low back pain patients, performance compared to healthy control subjects. Spine. 2010;35(5):583-9.

13. Beauchet O, Dubost V, Herrmann F, Rabilloud M, Gonthier R, Kressig RW. Relationship between dualtask related gait changes and intrinsic risk factors for falls among transitional frail older adults. Aging Clin Exp Res. 2005;17(4):270-5.

14. Chen CJ, Chou LS. Center of mass position relative to the ankle during walking: a clinically feasible detection method for gait imbalance. Gait \& Posture. 2010; 31(3):391-3.

15. Miyamoto ST, Lombardi Júnior I, Berg KO, Ramos LR, Natour J. Brazilian version of the Berg balance scale. Braz J Med Biol Res. 2004;37(9):1411-21.

16. Hermens JH, Freriks B, Disselhorst-Klug C, Rau G. Development of recommendations for SEMG sensors and sensor placement procedures. J Electromyogr Kinesiol. 2000;10:361-74.

17. Dingwell JB, Marin LC. Kinematic variability and local dynamic stability of upper body motions when walking at different speeds. J Biomech. 2006;39:44-52.

18. Kang HG, Dingwell JB. Separarating the effects of age and walking speed on gait variability. Gait \& Posture. 2008;27(4):572-7. 
19. Alexander NB, Hausdorff JM. Guest editorial: linking thinking, walking, and falling. J Gerontol A Biol Sci Med Sci. 2008;63:1325-8.

20. Yogev-Seligmann G, Hausdorff JM, Giladi N. The role of executive function and attention in gait. Mov Disord. 2008;23:329-42.

21. Nordin E, Moe-Nilssen R, Ramnemark A, Lundin-Olsson L. Changes in step-width during dual-task walking predicts falls. Gait \& Posture. 2010;32:92-7.

22. Nadkarni NK, Zabjek K, Lee B, Mcllroy WE, Black SE. Effect of working memory and spatial attention tasks on gait in healthy young and older adults. Motor Control. 2010;14:195-210.

23. Bassey, EJ. Physical capabilities, exercise and aging. Reviews in Clinical Gerontology. 1997;7:289-97.

24. Meuleman JR, Brechue WF, Kubilis PS, Lowenthal DT. Exercise training in the debilitates aged: strength and functional outcomes. Arch Phys Rehabil. 2000;81: 312-8.

25. Kang HG, Dingwell JB. Dynamics and stability of muscle activations during walking in healthy young and older adults. J Biomech. 2009;42:2231-7.

26. Fiatarone MA, Evans WJ. The etiology and reversibility of muscle dysfunction in the aged. J Gerontol. 1993;48S:77-83.

27. Schmitz A, Silder A, Heiderscheit B, Mahoney J, Thelen DG. Differences in lower-extremity muscular activaton during walking between healthy older and young adults. J Electromyogr Kinesiol. 2009;19:1085-91.

28. Helbostad JL, Leirfall S, Moe-Nilssen R, Sletvold O. Physical fatigue affects gait characteristics in older persons. J Gerontol A Biol Sci Med Sci. 2007;62A(9): 1010-5.
29. Maki BE. Gait changes in older adults: predictors of falls or indicators of fear. J Am Geriatr Soc. 1997; 45(3):313-20.

30. Dubost V, Kressig RW, Gonthier R, Herrmann FR, Aminian K, Najafi B, et al. Relationships between dual-task related changes in stride velocity and stride time variability in healthy older adults. Hum Mov Sci. 2006;25:372-82.

31. Montero-Odasso M, Casas A, Hansen KT, Bilski P, Gutmanis I, Wells JL, et al. Quantitative gait analysis under dual-task in older people with mild cognitive impairment: a reliability study. J NeuroEngineering and Rehabil. 2009;35(6).

32. Beauchet O, Allali G, Annweiler C, Bridenbaugh S, Assal F, Kressig RW, Herrmann FR. Gait variability among healthy adults: low and high stride-to-stride variability are both a reflection of gait stability. Gerontology. 2009;55:702-6.

33. Yogev-Seligmann G, Rotem-Galili Y, Mirelman A, Dickstein R, Giladi N, Hausdorff JM. How does explicit prioritization alter walking during dual-task performance? Effects of age and sex on gait speed and variability. Phys Ther. 2010;90(2):177-86.

34. Verghese J, Holtzer R, Lipton RB, Wang C. Quantitative gait markers and incident fall risk in older adults. J Gerontol A Biol Sci Med Sci. 2009;64(8): 896-901.

Received: $11 / 05 / 2011$

Recebido: 05/11/2011

Approved: 05/14/2015

Aprovado: 14/05/2015 
